\title{
Correction to: A Digital Workflow for Built Heritage: From SCAN-to-BIM Process \\ to the VR-Tour of the Basilica of Sant'Ambrogio in Milan
}

Fabrizio Banfi, Chiara Stanga, and Raffaella Brumana

\section{Correction to:}

Chapter "A Digital Workflow for Built Heritage:

From SCAN-to-BIM Process to the VR-Tour of the Basilica

of Sant'Ambrogio in Milan" in: M. Ioannides et al. (Eds.):

Digital Heritage. Progress in Cultural Heritage: Documentation, Preservation, and Protection, LNCS 11196, https://doi.org/10.1007/978-3-030-01762-0_28

The original version of the chapter 'A Digital Workflow for Built Heritage: From SCAN-to-BIM Process to the VR-Tour of the Basilica of Sant'Ambrogio in Milan' starting on p. 334 was revised.

The authors' names were incorrect. They should read as follows: Fabrizio Banfi, Chiara Stanga, and Raffaella Brumana.

The original article were corrected. 